\title{
The Challenge of Sustainable Development and the Imperative of Green and Inclusive Economic Growth
}

\author{
Michael Herrmann* \\ United Nations Population Fund (UNFPA), New York, USA \\ Email: mic.herrmann@gmail.com
}

Received December 31, 2013; revised January 31, 2014; accepted February 6, 2014

Copyright (c) 2014 Michael Herrmann. This is an open access article distributed under the Creative Commons Attribution License, which permits unrestricted use, distribution, and reproduction in any medium, provided the original work is properly cited. In accordance of the Creative Commons Attribution License all Copyrights (C) 2014 are reserved for SCIRP and the owner of the intellectual property Michael Herrmann. All Copyright (C) 2014 are guarded by law and by SCIRP as a guardian.

\begin{abstract}
The greatest challenge of the century is to meet the needs of current and future generations, of a large and growing world population, while at the same time ensuring the sustainability of the natural environment. The current development model places unsustainable pressures on the natural resources-forests, land, water and the atmosphere-and causes an increasing frequency and intensity of natural and humanitarian disasters. The paper agrees with increasing evidence that business-as-usual is not an option, but it takes issues with many of the suggested policy responses. Human wellbeing is inseparably linked to economic growth, and economic growth inevitably has environmental implications. While it is impossible to decouple these linkages, countries can promote more sustainable development pathways by altering these linkages. To this end, they have three principle policy levers, which will need to complement each other: Efforts to promote more inclusive economic growth, efforts to increase resource-efficiency, and efforts to address and harness demographic changes. The paper has important implications for the discussions on sustainable development goals and the post-2015 development agenda, which takes place at the United Nations.
\end{abstract}

\section{KEYWORDS}

\section{Green and Inclusive Economic Growth; Environment and Development; Demography; Sustainability}

\section{Introduction}

Humans are the central concern of sustainable development (Rio Declaration of 1992, principle 1), and their wellbeing should be our joint starting point in this discussion [1]. Regardless of the definition and measurement of human wellbeing, it is associated with the enjoyment of essential goods and services. In this sense, economic growth is an essential mean to social progress, and environmental damages are an undesired effect of economic growth. Sustainable development strategies must seek to strengthen the contribution of economic growth to social development, while lessening the impact of economic growth on the environment. These linkages are schema-

${ }^{*}$ Michael Herrmann is Senior Adviser on Population and Economics with the United Nations Population Fund (UNFPA). The paper benefited from valuable discussions with Jose Miguel Guzman, Ingo Pitterle Detlef Kotteand and Heiner Flassbeck. However, the views expressed in this paper are those of the author, and they do not necessarily reflect the views UNFPA. tically highlighted in Chart 1.

The greatest challenge of this century is to promote the wellbeing of current and future generations, of a large and growing world population, without imposing unsustainable pressures on the natural environment. The world population reached the 7 billion mark in 2011 and, according to the medium variant of population projections published by the Population Division of the United Nations, the world population will grow to over 9 billion by 2050 [2]. Accordingly, between now and 2050 almost as many people will be added to the planet as inhabited the planet as recently as 1950 . The challenges are particularly pronounced in the worlds' least developed countries, which have the world's highest population growth.

The projected growth in the world population masks considerable differences between countries. On the one extreme of the spectrum are the countries in Sub-Saharan Africa and South Asia, where fertility is still high and 
populations continue to grow rapidly; on the other are advanced countries in Europe and East Asia, where fertility is comparatively low and populations are aging. However, while the least developed countries are most immediately challenged by high population growth, all countries will feel its effects. The world is not only bound together by trade and financial flows, but also by demographic and environmental change. Efforts to meet a rapidly growing demand for water, food and energy, for example, will affect prices, production and natural resources in all countries. Likewise, failure to meet people's needs, reduce poverty, raise living standards and ensure greater equity will threaten stability, security and sustainability throughout the world. To address population dynamics requires not only political will from the countries where they occur, but also adequate support from their development partners.

In its first section the paper outlines the principle linkages between social, economic and environmental change, and in its second section it shows how these linkages are playing out in the world's least developed countries. Against this background the paper discuss the imperative for greener and more inclusive economic growth, as well as the need for rights-based population policies.

\section{Linkages between Social, Economic and Environmental Change}

Globally, about 1 out of 6 persons continue to live in extreme poverty with less than dollar 1.25 per day in purchasing power parities ${ }^{1}$, and about 1 in 8 persons still go to bed hungry [7]. Many suffer from food insecurity and live in slums, and millions cannot find productive and remunerative employment and therefore have inadequate household incomes, and access to essential goods and services. Meeting the needs of the people who currently inhabit the planet-especially the poor who suffer material deprivations that not only reduce the quality of their lives, but effectively shorten their life expectancy and cause physical and mental harm-and the people who will be added to the planet is the most significant developmental challenge. Meeting it, demands a more balanced distribution of economic resources, especially as inequalities and inequities are continuing to increase, but also requires higher and more sustained output growth.

Today, for instance, food security is still largely a question of distribution and access-the ability of households to go to a market and purchase the food they need-but food security is rapidly becoming a question

\footnotetext{
${ }^{1}$ There are considerable differences between poverty estimates. National-accounts consistent poverty estimates suggest a lower level of extreme poverty, especially in the emerging market countries. For a discussion of differences in methodologies, see UNCTAD [3,4], and Karshenas $[5,6]$.
}

of availability—-the capacity of the world economy to produce sufficient food to feed a growing world population. To feed a world population of 9 billion will require that agricultural output increases by about 70 per cent over current levels, according to a recent study by FAO $[8,9]$. But needed is not only a higher output of the agricultural sector, but also an increasing production of other goods and services. More people will also need more water and energy, clothing, housing and infrastructure, and health and education, amongst others.

It is an even bigger challenge to meet the needs of a large and growing world population without inflicting unsustainable environmental damages. Nothing can be produced from nothing, and everything that is produced will result in environmental change. This is true even for seemingly non-material goods such as knowledge, and services such as education and health care. Knowledge often depends on resource-intensive research and development; education requires books, computers and stationary; health care is unthinkable without medical machinery and pharmaceutical industries; and either demands physical infrastructure. The production of goods and services inevitably depends on the transformation of natural resources. This will place mounting pressures on all natural resources including water, land, forests and the climate, which are an essential as well as finite basis of life. Failure-the continuation of business as usual-is not an option. It would result in rising poverty and inequalities, or lead to unsustainable environmental degradation, and either would ultimately end in unimaginable humanitarian crises. Human kind has maneuvered itself between a rock and a hard place, but still has choices (Chart 1).

\section{Challenges in Least Developed Countries}

Although the world's least developed countries have the highest population growth, they have thus far contributed least to global greenhouse gas emissions. However, it would be hasty to conclude that population growth does not matter for greenhouse gas emissions, or that population growth does not have an environmental impact more broadly. The reason why the least developed countries have so far contributed little to global greenhouse gas emissions is chiefly attributable to the fact that the a large share of their populations continue to live in extreme poverty. ${ }^{2}$ It is population growth paired with the effort to reduce poverty and ensure adequate living conditions that will lead to mounting pressures on the atmosphere and other natural resources. The least developed countries are confronting the greatest challenges in

\footnotetext{
${ }^{2}$ According to survey-based poverty estimates, about 50 per cent of the population of the least developed countries continue to live with dollar 1.25 per person and day, adjusted for purchasing power differences [10].
} 
Principle linkages between social, economic and environmental development
Policy priorities for sustainable social, economic and environmental development

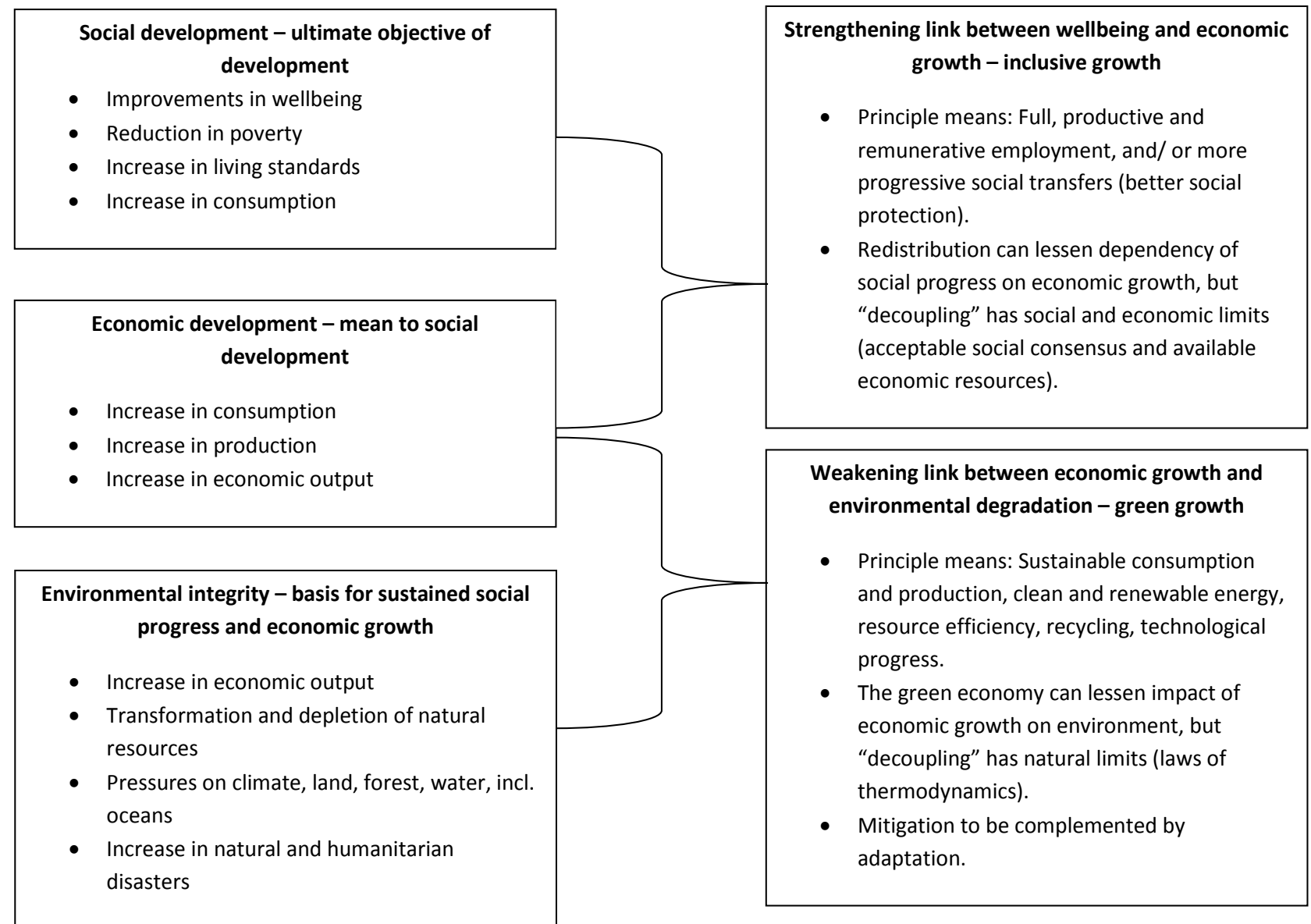

Chart 1. Conceptual framework of sustainable development and its policy implications.

poverty reduction, and at the same time they are confronting the greatest challenges in ensuring environmental sustainability.

Many people in the world's least developed countries are unable to even meet their basic needs. Many are unable to put food on the table or their children through school; many lack access to water and energy, sanitation and housing. Furthermore, while a comparatively small share of their population is outright unemployed, largely owing to the lack of (sufficient) unemployment benefits, the vast majorities of their populations hold unproductive or precarious jobs and suffer from underemployment or vulnerable employment. In the least developed countries today about 80 per cent of the people who are working are only vulnerably employed and no less than 60 per cent continue to live in extreme poverty despite of work [11]. These countries confront a staggering employment deficit, and the employment challenge will further grow over the next decades. Between now and 2050 their pop- ulation will double, their working-age population will expand by about 16 million persons per year, and their labor force will grow by approximately 33 thousand young persons each day [12].

Meeting the needs of the current and future population for goods, services and employment-which depend on higher economic output-while ensuring a sustainable use of natural resources has become the greatest developmental challenge today.Climate change is reinforcing exposure to natural hazards, including shifts in precipitation and an increase in desertification, impacting agriculture. But pressures on agricultural land, forests and water resources are not only attributable to climate change caused elsewhere; they are also attributable to the patterns of consumption and production in the poorest countries themselves. Many of these countries rely heavily on the exploitation of their natural resources to spur economic growth-notably extractive industries, largescale agriculture and timber production-and many of 
the poorest households also rely heavily on wood and other natural resources for their daily needs. The world's least developed countries are suffering most from a rapid degradation and depletion of their natural resources, and that this is effectively undermining a sustainable catch-up with more advanced countries [13]. Between 2000-2008, the average rate of real economic growth in the least developed countries was almost as high as in other developing countries ( 6.5 per cent compared with 6.6 per cent, respectively), but adjusted for population growth and environmental degradation and depletion it was almost half of what it was in other developing countries (2.5 per cent compared with 4.7 per cent respectively) (Chart 2).

A rapid shift towards the green economy is of great importance for a sustainable and sustained development of the world's least developed countries. Sustainable development pathways require not only sustainable patterns of production and consumption but also human-rights based policies to address population dynamics. Human-rights based policies, as outlined in the Cairo Programme of Action agreed at the International Conference on Population and Development include access to sexual and reproductive health care, including voluntary family planning, as well as the empowerment of women and youth.
The past decades where characterized by considerable progress in these areas, but in the least developed countries, particularly in Africa, progress has virtually stopped. The least developed countries have a high adolescent pregnancy rate, 121 births per 1000 girls of 15-19 years, compared with 52 in developing countries; a low contraceptive prevalence rate, 31 percent compared with 62 in developing countries; and a high rate of unmet need for family planning, 24 percent compared to 11 in developing countries [14].

But as regards the unmet need for family planning, there are not only important differences between the more and less advanced countries, there are also significant differences between the social strata within the poorest countries themselves. Data from demographic and health surveys undertaken in 1998 and again in 2008 in a total of 17 African LDCs show that women with a secondary or higher education, women in urban areas, and women of the wealthiest households are less likely to become mothers as adolescents, more likely to use contraceptives and less likely to have an unmet need for contraception than women with no or primary education, women in rural areas, or women of poor households.

The least developed countries have, on the one hand, a great need to invest in their populations, but they have,

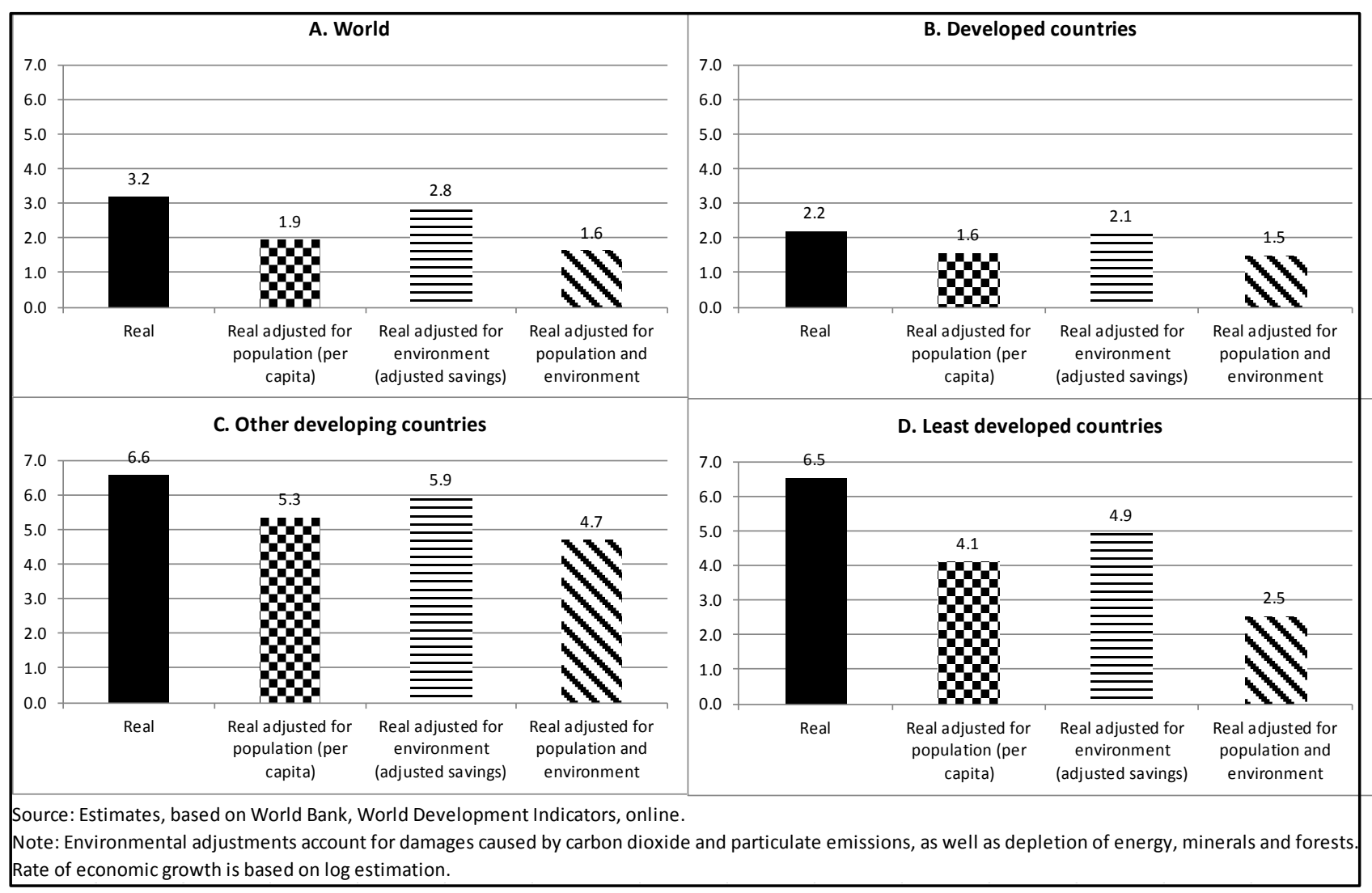

Chart 2. Average rate of real economic growth adjusted for population and environmental depletion and damages, average 2000-2008. 
on the other, very limited resources to do so. High population growth exacerbates these challenges. All countries, even the richest would find it extremely challenging if their populations were to double in the next forty years or so, the least developed countries will find this even more difficult. How can they hope to upkeep, let alone increase per-capita spending on health and education, on infrastructure, and on other essential goods and services? Yet, if there are unable to increase per-capita spending in these essential areas, they may not be able to secure past achievements-including the achievement of universal primary education - and may get stuck in a trap of poverty and underdevelopment. The ambition to break this trap does not represent an automatic call for, or justification of, human-rights violating population controls. Rather, it requires a balanced policy response, which focuses on promoting greener and more inclusive economic growth, and policies which focus on promoting sexual and reproductive health and rights and women's empowerment [15]. Demographic change is the cumulative result of individual choices and opportunities, and it is best addressed by enlarging individual choices and opportunities. This includes the ability of women to access sexual and reproductive health care, including voluntary family planning, and the education of in younger generations, including comprehensive sexuality education.

Two of these three principle policy levers were already emphasized by the Rio Declaration of 1992 (principle 8), as well as the Cairo Programme of Action of 1994 (principle 6) agreed at the International Conference on Population and Sustainable Development [16]: A shift towards sustainable patterns of production and consumptionwhich is the hallmark of the green economy-and policies to address population dynamics. But efforts to ensure environmentally sustainable consumption and production by and for a growing world population should also be complemented by efforts to ensure a more equitable distribution of goods and services. The following sections address these implications.

\section{The Imperative for Green and Inclusive Economic Growth}

While a continued rise in fuel prices will gradually encourage a shift away from carbon-intensive production and consumption, there is a great risk that this shift towards more sustainable production and consumption will come too late to avoid the overstepping of critical tipping points. The principle of precaution therefore dictates that governments actively promote sustainable consumption and production patterns by creating the necessary combination of incentives, disincentives and prohibitions. This will require a mix of economic instruments-notably fiscal policies and functioning emissions marketsand legal instruments-including environmental legis- lation and product standards.

While the discussions at the global level typically focus on the promotion of both green and inclusive economic growth, one is not necessarily associated with the latter. The ultimate purpose of the green economy is to reduce environmental pressures, and it would be overly optimistic, and demanding, to expect that the transition to the green economy will also reduce economic inequities. Although the transition to the green economy can be used to promote social inclusion, in many cases the green economy will not necessarily more or less inclusive than the brown economy. This fact does not make the green economy less important and urgent; it just means that we do not have a magic wand that can solve all our challenges simultaneously. Efforts to promote greener economies cannot substitute for the importance of social policies or vice versa.

Countries can reduce poverty and ensure adequate consumption levels through two principle means: More inclusive economic growth-by creating full, productive and remunerative employment which raises disposable household incomes-and more progressive social transfers. Although economic growth has resulted in falling poverty incidence in many countries, it failed to reduce poverty in others. The poverty-reducing effect of economic growth strongly depends on its employmentintensity, but is also determined by poverty incidence themselves, as poverty reduction becomes more difficult at the margin.

Even where the poor have benefited from economic growth, the rich have typically benefited more. Over the last decades income inequality and inequities have risen across the world. A more equitable distribution of goods and services (or income) can help to counteract this trend. However, there are social and economic limits to redistribution. What is an acceptable social consensus in the Nordic countries of Europe, for example, is hardly a feasible consensus in the United States of America. Furthermore, while even the poorest countries can and should encourage more equitable distribution, distribution there will also confront economic limits. ${ }^{3}$ On the one hand they have the highest poverty incidences, which call for large social transfers, but on the other they have limited economic resources to match the needs. In 2010, Eritrea's GDP, adjusted for purchasing power parities, amounted to only 1.3 dollars per person per day. In the same year and by the same measure, every person would have had only 3.1 dollars a day in the low-income countries, on average. ${ }^{4}$ This is too little to ensure access to essential goods and services, and material wellbeing.

${ }^{3}$ The desire of countries to maintain incentive structures is arguably another economic limit to distribution. However, most countries have considerable policy space between a weakening of economic incentive structures and the promotion of more equitable distribution. 
Distributive efforts must be complemented by higher economic growth, and for it to be sustainable higher economic growth must be accompanied by decreasing environmental pressures.

\section{The Need for Human Rights Based Population Policies}

Contrary to common perceptions, demography is not destiny, and can be addressed through human-rights based policies. Whether the world population will indeed grow to over 9 billion by mid-century and level off at about 10 billion by the end of the century, or grow instead to over 10 billion by mid-century and to about 16 billion by the end of the century depends on policies that countries pursue today. The differences between the former (the medium variant of the United Nations population projecttions), and the latter (the high variant of its population projections) is but half a child per woman, less or more on average [17]. Every decade of delay in reaching replacement-level fertility implies continued, significant population growth for decades to come.

Essential and effective rights-based policies to address population dynamics ensure access to sexual and reproductive health care, including family planning; investment in education beyond the primary level; and the empowerment of women and young people. Special effort must be made to ensure that girls are not left behind. Together these measures will help to improve the quality of life of people. They will help to curb infant, child and maternal mortality; the spread of communicable diseases; unintended pregnancies of adolescents; the psychological, physical and financial burden of diseases; and they will also contribute lower fertility, slower population growth, demographic transition and more sustainable development.

However, even if fertility levels were to instantaneously drop to replacement levels, because of the sheer number of women in child-bearing age the populations will continue to grow for decades to come. In the poorest countries, rural populations will continue to grow, but urban populations will grow at an even faster pace. Furthermore, many countries are already witnessing the rapid aging of their populations, an accelerated rate of urbanization, and an increase in migration, which fundamentally affect all aspects of social, economic and political life. To address associated challenges and harness associated opportunities countries will need to systematically use population projections to inform rural, urban and national development strategies, plans and policies.

If countries anticipate and plan for demographic change, rather than react to it as it unfolds, demographic

${ }^{4}$ Calculation based on World Bank, World Development Indicators, online. change can contribute to sustainable social, economic and environmental development. A fall in fertility will temporarily reduce dependency ratios and open up a window of opportunity for households and countries to increase investment in people and productive capacities. Furthermore, migration can ease pressures on natural resources and enable people to adapt to changes in economic and environmental conditions. And urban population growth-in many of the poorest countries it is accelerated by a rapid rate of rural-to-urban migration can also positively contribute to sustainable development. As populations increase, it makes economic and environmental sense for people to move closer together in urban areas. There, governments can deliver essential goods and services at lower costs per capita than in rural areas and population consume less energy, adjusted for income, than in rural areas. Energy savings are particularly significant in the housing and transport sectors.

\section{Implications}

As the Millennium Development Goals that the world agreed on in 2000 are set to expire, the world leaders are debating a new development agenda for the era post 2015. While the policy makers recognized that this new development agenda must focus on promoting sustainable development-which is defined as a sustainable and harmonious balance between social, economic and environmental change- the discussions on how to achieve this remains confused. This is largely due to the fact that many do not have a clear understanding of how social, economic and environmental changes are linked, and therefore lack and understanding of how to make these linkages more sustainable. This paper contributes to both.

These three dimensions of sustainable development, the social, economic and environmental, are inseparably linked with each other. Social development-the improvement in the wellbeing of current and future generations -is the ultimate objective of development. However, social development is not possible without economic development-the production of goods and services-and economic development cannot be entirely delinked from environmental change- the transformation, degradation and depletion of natural resources. Ensuring sustainable development pathways requires deceive policy interventions, which must focus on promoting greener and more inclusive economic growth, and addressing population challenges through rights-based approaches.

\section{REFERENCES}

[1] UN, Report of the United Nations Conference on Environment and Development, Rio de Janeiro, 3-14 June 1992, A/CONF.151/26 (Vol. I), 12 August 1992

[2] UN Population Division, World Population Prospects: 
The 2012 Revision, 2013.

http://esa.un.org/unpd/wpp/index.htm

[3] UNCTAD, The Least Developed Countries Report 2002: Escaping the Poverty Trap, Geneva, 2002.

[4] UNCTAD, The Least Developed Countries Report 2008: Growth, Poverty and the Terms of Development Partnership, Geneva, 2008.

[5] M. Karshenas, "Global Poverty: National Accounts Based versus Survey Based Estimates," Development and Change, Vol. 34, No. 4, 2003, pp. 683-712. http://dx.doi.org/10.1111/1467-7660.00324

[6] M. Karshenas, "Global Poverty: Towards a Unified Approach,” Journal of Income Distribution, Vol. 19, No. 2, 2010, pp. 3-32.

[7] UN, The Millennium Development Goals Report 2013, New York.

[8] FAO, FAO at work 2009-2010: Growing food for nine billion, Rome, 2010.

[9] M. Herrmann and R. Peters, "Impact of Food Crisis on Developing Countries and Implications for Agricultural Trade Policy,” In: B. Karapinar and C. Haeberli, Eds., Food Cries and the WTO: World Trade Forum, Cambridge University Press, Cambridge, 2009.

[10] UN, "Monitoring of Population Dynamics, Focusing on Health, Morbidity, Mortality and Development," Report of the Secretary-General to the Commission on Population and Development, 43rd Session, 12-16 April 2010,
New York.

[11] ILO, "Growth, Employment and Decent Work in the Least Developed Countries,” Report of the International Labour Office for the Fourth Conference on the Least Developed Countries, Istanbul, 9-13 May 2011.

[12] UNFPA, "Population Dynamics in the Least Developed Countries: Challenges and Opportunities for Development and Poverty Reduction,” Report of the United Nations Population Fund for the Fourth Conference on the Least Developed Countries, Istanbul, 9-13 May 2011.

[13] UNFPA, "Population Matters for Sustainable Development," New York, 2012.

[14] UNFPA, "Population Dynamics in the Least Developed Countries: Challenges and Opportunities for Development and Poverty Reduction," Report of the United Nations Population Fund for the Fourth Conference on the Least Developed Countries, Istanbul, 9-13 May 2011.

[15] M. Herrmann, "Factoring Population Dynamics into Sustainable Development,” OECD, Development Co-Operation Report 2012: Lessons in Linking Sustainability and Development, Paris.

[16] UN, Report of International Conference on Population and Development, Cairo, 5-13 September 1994, 18 October 1994

[17] UN Population Division, World Population Prospects: The 2012 Revision, 2013. http://esa.un.org/unpd/wpp/index.htm 